\title{
White Matter Diffusion Changes during the First Year of Natalizumab Treatment in Relapsing-Remitting Multiple Sclerosis
}

\author{
O.T. Wiebenga, (DM.M. Schoonheim, DH.E. Hulst, G.J.A. Nagtegaal, (D) E.M.M. Strijbis, (D) M.D. Steenwijk, (DC.H. Polman, \\ (DP.J.W. Pouwels, DF. Barkhof, and (D).J.G. Geurts
}

\begin{abstract}
BACKGROUND AND PURPOSE: Natalizumab treatment strongly affects relapsing-remitting multiple sclerosis, possibly by restraining white matter damage. This study investigated changes in white matter diffusivity in patients with relapsing-remitting multiple sclerosis during their first year of natalizumab treatment by using diffusion tensor imaging.
\end{abstract}

MATERIALS AND METHODS: The study included patients with relapsing-remitting multiple sclerosis initiating natalizumab at baseline ( $n=22$ ), patients with relapsing-remitting multiple sclerosis continuing interferon- $\beta$ or glatiramer acetate $(n=17)$, and healthy controls $(n=12)$. Diffusion tensor imaging parameters were analyzed at baseline and month 12 . We measured the extent and severity of white matter damage with diffusion tensor imaging parameters such as fractional anisotropy, comparing the patient groups with healthy controls at both time points.

RESULTS: The extent and severity of white matter damage were reduced significantly in the natalizumab group with time (fractional anisotropy-based extent, $56.8 \%$ to $47.2 \%$; severity, $z=-0.67$ to $-0.59 ; P=.02$ ); this reduction was not observed in the interferon- $\beta$ / glatiramer acetate group (extent, $41.4 \%$ to $39.1 \%$, and severity, $z=-0.64$ to $-0.67 ; P=.94$ ). Cognitive performance did not change with time in the patient groups but did correlate with the severity of damage $(r=0.53, P=<.001)$.

CONCLUSIONS: In patients with relapsing-remitting multiple sclerosis starting natalizumab treatment, the extent and severity of white matter damage were reduced significantly in the first year of treatment. These findings may aid in explaining the large observed clinical effect of natalizumab in relapsing-remitting multiple sclerosis.

ABBREVIATIONS: $\mathrm{AD}=$ axial diffusivity; $\mathrm{EDSS}=$ Expanded Disability Status Scale; $\mathrm{FA}=$ fractional anisotropy; $\mathrm{GA}=$ glatiramer acetate; $\mathrm{IFNb}=$ interferon $\beta ; \mathrm{NBV}=$ normalized whole-brain volume; $\mathrm{MD}$ = mean diffusivity; $\mathrm{RCI}=$ Reliable Change Index; $\mathrm{RD}$ = radial diffusivity; RRMS = relapsing-remitting multiple sclerosis

$M^{\prime \prime}$ ultiple sclerosis is an inflammatory demyelinating disease of the central nervous system, characterized by focal damage and atrophy of the white ${ }^{1}$ and gray matter. ${ }^{2}$ Physical and

Received August 17, 2015; accepted after revision November 12.

From the Departments of Radiology and Nuclear Medicine (O.T.W., G.J.A.N. ${ }^{\dagger}$, M.D.S., F.B.), Anatomy and Neurosciences (O.T.W., M.M.S., H.E.H., G.J.A.N. ${ }^{\dagger}$, J.J.G.G.), Neurology (E.M.M.S., C.H.P.), and Physics and Medical Technology (P.J.W.P.), Neuroscience Campus Amsterdam, VU University Medical Center, Amsterdam, the Netherlands.

†Deceased.

This investigator-initiated study was sponsored by the Dutch MS Research Foundation, grant number 09-358d. MR imaging was partly sponsored by Biogen Idec.

Biogen Idec did not participate in any aspect of the design or performance (including data collection, data management, data analysis and interpretation, or preparation) of this investigator-initiated study. Final approval for the work and article was given by the authors.

Please address correspondence to Oliver T. Wiebenga, MD, VU University Medical Center, Department of Radiology and Nuclear Medicine, PO Box 7057, 1007 MB, Amsterdam, the Netherlands; e-mail: o.wiebenga@vumc.nl

Indicates article with supplemental on-line photo.

http://dx.doi.org/10.3174/ajnr.A4690 cognitive dysfunction starts early in the disease, ${ }^{3}$ with a strong impact on the quality of life. ${ }^{4}$ Conventional MR imaging measures, such as lesion load, only modestly relate to patient functioning and progression. Recent advanced MR imaging techniques such as diffusion tensor imaging have shown better correlations with clinical outcomes, partly due to the demonstration of subtle abnormalities in the normal-appearing white matter. ${ }^{5-8}$

Natalizumab is a second-line (in most countries) treatment option for relapsing-remitting multiple sclerosis (RRMS), which has been shown to have strong anti-inflammatory effects because it prevents leukocytes from penetrating the blood-brain barrier, reducing the formation of new WM lesions ${ }^{9}$ and possibly preventing more subtle damage in the normal-appearing white matter. In doing so, natalizumab may lead to a more advantageous environment for axonal repair and remyelination in the normal-appearing white matter, which can only be measured with more advanced imaging techniques such as DTI. This process might explain how natalizumab seems to affect clinical measures, such as reducing the number of relapses and the progression of disability. ${ }^{10}$ 
In this study, we investigated the effects of natalizumab on the evolution of WM damage in the first year of treatment by measuring the extent and severity of WM damage by using DTI. Patients starting natalizumab treatment were scanned at baseline and after 1 year. A patient group continuing standard diseasemodifying-drugs (ie, interferon- $\beta$ or glatiramer acetate [IFNb/ GA]) was also included. Both patient groups were compared with healthy controls.

\section{MATERIALS AND METHODS Study Design}

The study was a prospective and observational study with 2 time points: baseline and month 12 . The study population consisted of 22 patients with RRMS initiating natalizumab treatment and 12 healthy controls, age- and sex-matched to the patients. Before switching to natalizumab, 13 patients were receiving IFNb and 9 patients were receiving GA. To provide insight into the normal evolution of WM pathology in MS, we included 17 patients with RRMS following and continuing IFNb/GA. Patients receiving IFNb/GA were pooled (IFNb $n=11$ and GA $n=6$ ) and were matched to the patients initiating natalizumab for age, sex, disability (Expanded Disability Status Scale $[\text { EDSS }]^{11}$ ), and duration of prior IFNb/GA exposure.

Inclusion criteria for the patients with RRMS were a diagnosis of clinically definite MS $^{12}$ and being between 18 and 65 years of age. Exclusion criteria were the presence or history of psychiatric or neurologic disease (besides MS) and the presence or history of alcohol or drug abuse. The study protocol was approved by the institutional ethics review board of our center, and informed consent was obtained from all participants.

No serious or unanticipated adverse events attributed to MS medication developed in the patient groups.

\section{Study Population}

Patients initiating natalizumab at the outpatient neurology clinic of our center were screened according to the indication criteria used at our institution. These included at least 1 prior period of IFNb or GA with break-through disease with $\geq 1$ relapse or rapidly evolving active RRMS defined by the occurrence of $\geq 2$ relapses. Patients were only included in the study once the decision to start natalizumab treatment had already been made. At the baseline measurement, 6 patients were treatment-naïve for natalizumab; 13 patients had received 1, and 3 patients, 2 infusions. All patients continued natalizumab treatment (300 mg IV once every 4 weeks) for the duration of the study.

Patients receiving IFNb/GA were already receiving and continuing IFNb/GA as their regular medical treatment. Eleven patients were continuing IFN-b-1a/b (dose and route of administration dependent on type), and 6 patients were continuing GA (20 mg subcutaneous once daily). One patient from this group discontinued GA before the month 6 visit because of radiologic and clinically stable disease combined with occurrence of adverse effects (necrosis and scarring of the skin at injection sites). Another patient discontinued IFNb-1a 1 month before the month 12 visit due to conversion to secondary-progressive MS. Both patients remained in the study.

\section{MR Imaging}

All imaging was performed on a $1.5 \mathrm{~T}$ whole-body scanner (Sonata; Siemens, Erlangen, Germany) by using an 8-channel phased array head coil. Structural imaging sequences included a 3D-T1weighted magnetization-prepared rapid acquisition of gradient echo sequence (TR, $2.700 \mathrm{~ms}$; TE, 5 ms; TI, $950 \mathrm{~ms}$; 176 sagittal sections with 1.3 -mm section thickness; $1.3 \times 1.3 \mathrm{~mm}^{2}$ in-plane resolution) for brain volume measurements and an axial turbo spin-echo proton-density/T2-weighted sequence (TR, $3.130 \mathrm{~ms}$; TE, 24 and $85 \mathrm{~ms}$; 46 contiguous $3-\mathrm{mm}$ sections; $1 \times 1 \mathrm{~mm}^{2}$ in-plane resolution) for WM lesion detection. Diffusionweighted echo-planar images (TR, $8.500 \mathrm{~ms}$; TE, $86 \mathrm{~ms}$; isotropic resolution, $2 \times 2 \times 2 \mathrm{~mm}$ ) were acquired with 60 volumes with noncollinear diffusion gradients (b-value of $700 \mathrm{~s} / \mathrm{mm} 2$ ) and 10 volumes without directional weighting.

\section{Brain and Lesion Volumes}

T2-hyperintense WM lesions were quantified by using an automated segmentation method. ${ }^{13}$ Normalized whole-brain (NBV), WM, and GM volumes were calculated by using the T1weighted images and SIENAX (http://fsl.fmrib.ox.ac.uk/fsl/fslwiki/ SIENA $)^{14}$ Brain volumes were calculated after lesion filling, by using(part of FSL, Version 5.02; http://www.fmrib.ox.ac.uk/fsl). Brain volumes were calculated after lesion filling, by using an automated lesion-filling technique (Lesion Automated Preprocessing). ${ }^{15}$

\section{Extent and Severity of WM Integrity Damage}

The diffusion parameters fractional anisotropy (FA), mean diffusivity (MD), axial diffusivity (AD), and radial diffusivity (RD) were derived for each voxel by fitting a tensor model to the raw diffusion data after motion and eddy current correction. For statistical comparisons, Tract-Based Spatial Statistics (TBSS; http:// fsl.fmrib.ox.ac.uk/fsl/fslwiki/TBSS), ${ }^{16}$ part of FSL, was used, in which all subjects' FA maps were aligned into a common space. The mean FA image was thinned to create a mean FA skeleton and thresholded at an FA of 0.2. Each subject's aligned FA and diffusivity data were then projected onto this WM skeleton, and the resulting data were fed into the FSL Randomize tool (http://fsl. fmrib.ox.ac.uk/fsl/fslwiki/Randomise).

At both time points, cross-sectional group differences in FA and MD of the mean WM skeleton were analyzed by using Randomize (500 permutations) by using a family-wise error-corrected threshold of $P<.05$ and correcting for age and sex.

Following the TBSS pipeline, we calculated the extent and severity of damage as follows:

1) The "extent" of damage was calculated per group, by calculating the percentage of significantly abnormal $(P<.05)$ voxels within the WM skeleton for the diffusion parameters FA and MD, compared with healthy controls.

2) The "severity" of damage within the WM skeleton was calculated per patient by converting the diffusion measures FA and MD to $z$ scores on the basis the mean and SDs of healthy control voxels. A single whole-skeleton mean $z$ score was calculated for the diffusion parameters $\mathrm{FA}$ and $\mathrm{MD}$, indicating the severity of damage across the entire WM skeleton per subject. As a post hoc 
exploration, the severities of $\mathrm{AD}$ and $\mathrm{RD}$ were additionally calculated at both time points.

\section{Neuropsychological Evaluation}

All subjects underwent an elaborate neuropsychological assessment on the day of scanning. The cognitive domains most frequently affected in MS were investigated by using tests from Rao's Brief Repeatable Battery for Neurologic Disease, ${ }^{17}$ including the Symbol Digit Modalities Test for information-processing speed, the Spatial Recall Task (SPART 10/36) for visuospatial memory, and the Word List Generation test for verbal fluency. Additionally, the Verbal Learning and Memory Task (the Dutch equivalent of the California Verbal Learning Test for verbal memory), the Stroop Color and Word Test for attention and inhibition, the Digit Span Forward and Digit Span Backward (part of the Wechsler Adult Intelligence Scale) for working memory, and the Delis-Kaplan Executive Function System Trail-Making Test for executive functioning were administered. Parallel versions were used for the different subtests when available (Symbol Digit Modalities Test, SPART 10/36, and Verbal Learning and Memory Task).

To uniformly quantify the deviation compared with test or subtest scores of the healthy controls, we converted the test or subtest raw baseline scores to $z$ scores. An average (overall) cognition $z$ score was also calculated.

The raw test or subtest scores were converted to Reliable Change Indices (RCI) to correct subtle learning effects in the longitudinal analysis. ${ }^{18}$ With this method, the reliable change on an individual test score is based on the difference between baseline and retest scores for the normative subject sample. RCI was computed as follows:

$$
R C I=\left\{\left[X_{2}-X_{1}\right]-[\text { mean }(\text { hc2 })-\text { mean }(\text { hc1 })]\right\} / \text { SED }
$$

where $X$ is a single-subject test score, mean[hc] is the mean of the healthy controls' test scores, and 1 and 2 are the different time points at which cognitive testing was performed. The SD of the mean $\Delta$ score of the healthy controls was used as the standard error of the difference score (SED).

An RCI score above zero indicates a better performance, whereas an RCI score below zero indicates a worse performance than can be expected by the normal learning curve of healthy controls.

\section{Patient Reported Outcome Measures}

Fatigue and symptoms of anxiety and depression were measured by using the Checklist Individual Strength ${ }^{19}$ and the Hospital Anxiety and Depression Scale ${ }^{20}$ questionnaires, respectively.

\section{Statistical Analysis}

Statistical analyses were performed with SPSS for Windows, Version 20.0 (IBM, Armonk, New York). When the variables were normally distributed, a multivariate GLM was used to test for group differences, with age, sex, and education included as covariates. Longitudinal analyses were performed by using paired $t$ tests comparing baseline with month 12 . Nonparametric analysis was performed by using the Kruskall-Wallis and (post hoc) Mann-Whitney tests. All analyses were Bonferroni-corrected, and $P<.05$ was considered statistically significant.

\section{RESULTS}

\section{Descriptives and Clinical Scores}

At baseline, the 3 groups did not differ on age and sex (Table 1). Compared with the healthy controls, patients with RRMS had more depressive symptoms (Hospital Anxiety and Depression Scale-Depression: natalizumab, $P=.004$; IFNb/GA, $P=.007$ ) and fatigue (Checklist Individual Strength: natalizumab, $P=$ .006; IFNb/GA, $P=.001$ ) and a slightly lower level of education (natalizumab, $P=.008$; IFNb/GA, $P=.014$ ). There were no differences between the patient groups for any of these measures or for EDSS, disease duration, and duration of prior IFNb/GA.

After 1 year, EDSS scores remained stable at 3.0 in patients receiving natalizumab, while the depression score (Hospital Anxiety and Depression Scale-Depression) significantly improved from 4.5 to $2.0(P=.012$, Table 2$)$. In patients receiving IFNb/GA, EDSS scores significantly deteriorated from 2.5 to $3.0(P=.006)$ with no change in depression. Fatigue levels remained constant for both groups.

\section{Brain and Lesion Volumes}

At baseline, only the IFNb/GA group showed lower NBV compared with controls $(P=.022)$, while both patient groups had lower normalized WM volume (natalizumab, $P=.044$; IFNb/GA, $P=.024)$. After 12 months, a further reduction was seen in both patient groups for normalized WM volume (natalizumab, $P=$ .008 ; IFNb/GA, $P=.004$ ) and NBV (natalizumab, $P=.036$; IFNb/GA, $P<.001)$. T2-lesion volumes remained stable in patients receiving natalizumab $(P=.644)$ but increased in the IFNb/GA group $(P=.012$, Table 3$)$.

\section{DTI: Extent of WM Damage}

At baseline, patients receiving natalizumab had reduced FA in $56.8 \%$ of the investigated WM skeleton voxels, including major WM bundles of the corpus callosum, the capsula externa, forceps major, corticospinal tract, corona radiata, and superior longitudinal fasciculus (Fig 1). At month 12, this dropped to $47.2 \%$. For MD, the extent with time was $54.3 \%$ and $55.7 \%$, respectively (Fig 2). Increased MD was generally seen in those parts of the WM skeleton where the FA was also decreased. Patients receiving IFNb/GA had reduced FA in $41.4 \%$ of the skeleton at baseline and $39.1 \%$ at month 12 ; for $\mathrm{MD}$, this was $33.7 \%$ and $36.1 \%$. Affected areas overlapped with the regions damaged in the natalizumab group but were generally smaller.

\section{DTI: Severity of WM Damage}

In the patients receiving natalizumab, the severity of FA damage at baseline was $z=-0.67$. At month 12 , however, the severity was reduced to $z=-0.59(P=.02$ compared with baseline, Table 3$)$, indicating that regional FA values were improved in these patients. In the patients receiving IFNb/GA, the severity remained stable at both time points, from $z=-0.64$ to -0.67 , with no significant change with time $(P=.94)$.

No significant changes in whole-skeleton $\mathrm{MD}, \mathrm{AD}$, and $\mathrm{RD}$ severity $z$ scores of WM damage were found in any group between baseline and month 12 (Table 3 ). 
Table 1: Baseline variables of patients with MS and controls (mean) ${ }^{\mathrm{a}}$

\begin{tabular}{|c|c|c|c|c|}
\hline & $\begin{array}{l}\text { Patients with Natalizumab } \\
\qquad(n=22)\end{array}$ & $\begin{array}{l}\text { Patients with IFNb/GA } \\
\qquad(n=17)\end{array}$ & $\begin{array}{l}\text { Healthy Controls } \\
\qquad(n=12)\end{array}$ & $P$ Value \\
\hline MS therapy & $\begin{array}{c}\text { Starting natalizumab } \\
\text { at baseline }\end{array}$ & $\begin{array}{c}\text { Continuing IFNb/GA } \\
\text { at baseline }\end{array}$ & NA & \\
\hline \multicolumn{5}{|l|}{ Descriptives } \\
\hline Age (yr) & $37.2 \pm 8.8$ & $38.2 \pm 5.0$ & $35.1 \pm 5.3$ & .492 \\
\hline Sex (male/female) ${ }^{b}$ & 9:13 & $8: 9$ & $3: 9$ & .322 \\
\hline Education ${ }^{\mathrm{c}}$ (mean) (range) & $6.0(4-7)$ & $6.0(5-7)$ & $7.0(5-7)$ & $.016^{\mathrm{e}}$ \\
\hline HADS-A ${ }^{c}$ (mean) (range) & $6.0(1-13)$ & $6.6(1-14)$ & $4.8(1-12)$ & .369 \\
\hline HADS-D ${ }^{c}$ (mean) (range) & $4.5(0-18)$ & $5.0(0-12)$ & $1.8(0-10)$ & $.008^{\mathrm{e}}$ \\
\hline $\mathrm{CIS}-20^{\complement}$ (mean) (range) & $68.5(14-125)$ & $86(31-114)$ & $42.5(17-85)$ & $.002^{\mathrm{e}}$ \\
\hline \multicolumn{5}{|l|}{ MS characteristics } \\
\hline $\mathrm{EDSS}^{\mathrm{b}, \mathrm{c}}$ & $3.0(1.5-6.5)$ & $2.5(1.0-6.5)$ & NA & .615 \\
\hline Disease duration since onset (yr) & $8.3 \pm 6.2$ & $9.1 \pm 5.2$ & NA & .662 \\
\hline Prior IFNb/GA duration at baseline (yr) & $2.9 \pm 3.1$ & $4.5 \pm 4.0$ & NA & .169 \\
\hline \multicolumn{5}{|l|}{ Volumes } \\
\hline NGMV (L) & $0.75 \pm 0.04$ & $0.73 \pm 0.06$ & $0.77 \pm 0.04$ & .134 \\
\hline NWMV (L) & $0.69 \pm 0.04$ & $0.69 \pm 0.04$ & $0.73 \pm 0.03$ & $.020^{\mathrm{e}}$ \\
\hline NBV $(L)$ & $1.44 \pm 0.06$ & $1.42 \pm 0.08$ & $1.50 \pm 0.06$ & $.025^{f}$ \\
\hline $\mathrm{T} 2$ lesion volume $(\mathrm{mL})^{\mathrm{d}}$ & $6.2(2.4-14.9)$ & $4.9(2.5-12.0)$ & NA & .281 \\
\hline \multicolumn{5}{|l|}{ Cognition z scores } \\
\hline Symbol Digit Modalities Test & $-2.17 \pm 0.92$ & $-1.71 \pm 1.13$ & $0.00 \pm 1.00$ & $<.001^{\mathrm{e}}$ \\
\hline SPART-total recall & $-1.90 \pm 1.94$ & $-0.82 \pm 1.83$ & $0.00 \pm 1.00$ & $.021^{8}$ \\
\hline SPART-delayed recall & $-1.42 \pm 1.57$ & $-0.80 \pm 1.93$ & $0.00 \pm 1.00$ & .076 \\
\hline VLGT-immediate recall & $-1.33 \pm 1.84$ & $-1.66 \pm 1.53$ & $0.00 \pm 1.00$ & .052 \\
\hline VLGT-short-term free recall & $-1.66 \pm 1.89$ & $-1.40 \pm 1.64$ & $0.00 \pm 1.00$ & .068 \\
\hline VLGT-long-term free recall & $-1.65 \pm 1.86$ & $-1.48 \pm 1.72$ & $0.00 \pm 1.00$ & .070 \\
\hline WLG-Animals & $-0.97 \pm 0.73$ & $-0.75 \pm 0.81$ & $0.00 \pm 1.00$ & $.019^{g}$ \\
\hline WLG-Professions & $-1.69 \pm 1.15$ & $-1.79 \pm 1.58$ & $0.00 \pm 1.00$ & $.001^{e}$ \\
\hline WLG-4 letter " $M$ " words & $-0.81 \pm 1.0$ & $-0.85 \pm 0.94$ & $0.00 \pm 1.00$ & .072 \\
\hline Digit Span Forward & $-0.62 \pm 1.06$ & $-0.29 \pm 0.98$ & $0.00 \pm 1.00$ & .670 \\
\hline Digit Span Backward & $-0.96 \pm 1.13$ & $-0.05 \pm 1.36$ & $0.00 \pm 1.00$ & .067 \\
\hline TMT-Letter-Number Switching & $-2.33 \pm 2.45$ & $-1.58 \pm 2.08$ & $0.00 \pm 1.00$ & .059 \\
\hline Stroop-interference & $-0.28 \pm 1.44$ & $-0.63 \pm 1.25$ & $0.00 \pm 1.00$ & .697 \\
\hline Average cognition & $-1.61 \pm 0.73$ & $-1.22 \pm 1.01$ & $0.00 \pm 1.00$ & $<.001^{\mathrm{e}}$ \\
\hline
\end{tabular}

Note:-CIS-20 indicates Checklist for Individual Strength questionnaire; HADS, Hospital Anxiety and Depression Scale; A, Anxiety; D, Depression; SPART, Spatial Recall Task; NGMV, normalized gray matter volume; NWMV, normalized white matter volume; VLGT, Verbal Memory and Learning Task; WLG, Word List Generation; TMT, Trail-Making Test; L, liter; NA, not applicable.

a When normally distributed, a multivariate General Linear Model was used with age, sex, and education included as covariates; General Linear Model main effect $P$ values are shown. Nonparametric testing was performed using the Kruskall-Wallis and post hoc Mann-Whitney tests. $P$ values $<.05$ are considered significant.

${ }^{\mathrm{b}} \chi^{2}$ test.

${ }^{c}$ Median and range.

${ }^{\mathrm{d}}$ Median and interquartile range.

e Significant in both patient groups compared with healthy controls.

${ }^{f}$ Only significant between patients receiving IFNb/GA and healthy controls.

${ }^{8}$ Only significant between patients receiving natalizumab and healthy controls.

Table 2: Clinical scales of baseline and month 12 (median and range) ${ }^{\mathrm{a}}$

\begin{tabular}{lrcccc}
\multicolumn{1}{c}{ Time Point } & \multicolumn{2}{c}{ Baseline } & \multicolumn{1}{c}{ Month 12 } & $P$ Value \\
\hline Patients on natalizumab & & & & & \\
$\quad$ EDSS & 3.0 & $(1.5-6.5)$ & 3.0 & $(1.0-6.5)$ & 1.0 \\
HADS-A & 6.0 & $(1-13)$ & 6.0 & $(0-15)$ & 1.0 \\
HADS-D & 4.5 & $(0-18)$ & 2.0 & $(0-17)$ & $.012^{\mathrm{b}}$ \\
CIS-20 & 68.5 & $(14-125)$ & 62.0 & $(10-117)$ & .036 \\
Patients on IFNb/GA $(n=17)$ & & & & & \\
$\quad$ EDSS & 2.5 & $(1.0-6.5)$ & 3.0 & $(1.5-7.0)$ & $.006^{\mathrm{b}}$ \\
HADS-A & 7.0 & $(1-14)$ & 5.0 & $(1-11)$ & .609 \\
HADS-D & 5.0 & $(0-12)$ & 3.0 & $(0-14)$ & .855 \\
CIS-20 & 86.0 & $(31-114)$ & 81.0 & $(16-105)$ & .177 \\
Healthy controls $(n=12)$ & & & & & \\
HADS-A & 3.5 & $(1-12)$ & 2.5 & $(0-9)$ & 1.0 \\
HADS-D & 1.0 & $(0-10)$ & 0.0 & $(0-5)$ & 1.0 \\
CIS-20 & 42.5 & $(17-85)$ & 52.0 & $(17-82)$ & .744 \\
\hline
\end{tabular}

Note:-CIS-20 indicates Checklist Individual Strength questionnaire; HADS, Hospital Anxiety and Depression Scale; A, Anxiety; D, Depression.

a EDSS, HADS, and CIS were tested with the related-samples Wilcoxon signed rank test (Bonferroni-corrected).

b Significant difference.

\section{Cognition}

At baseline, both patient groups had lower $z$ scores for the Symbol Digit Modalities Test (natalizumab, $P=$ $.001 ; \mathrm{IFNb} / \mathrm{GA}, P<.001)$ and the Word List Generation-Professions (natalizumab, $P=.003 ; \mathrm{IFNb} / \mathrm{GA}, P=$ .002) (Table 1) compared with healthy controls. The average cognition $z$ score was significantly lower for both patient groups (natalizumab, $P<.001$; IFNb/GA, $P=.005)$ compared with the healthy controls, but no difference between the patient groups $(P=.370)$ was found.

Overall, cognition scores were stable with time for both groups (Table 4), apart from the immediate recall of the 
Table 3: DTI and volumetric variables of baseline and month 12 visit (mean)

\begin{tabular}{|c|c|c|c|}
\hline & Baseline & Month 12 & $P$ Value \\
\hline \multicolumn{4}{|c|}{ Patients on natalizumab ( $n=22)$} \\
\hline FA severity ( $z$ score) & $-0.67 \pm 0.65$ & $-0.59 \pm 0.69$ & $.02^{\mathrm{a}}$ \\
\hline MD severity ( $z$ score) & $0.89 \pm 0.92$ & $0.93 \pm 0.98$ & .81 \\
\hline AD severity (z score) & $0.36 \pm 0.40$ & $0.43 \pm 0.39$ & .34 \\
\hline RD severity (z score) & $0.94 \pm 1.00$ & $0.94 \pm 1.07$ & 1.0 \\
\hline NGMV (L) & $0.75 \pm 0.04$ & $0.75 \pm 0.05$ & 1.0 \\
\hline NWMV (L) & $0.69 \pm 0.04$ & $0.67 \pm 0.03$ & $.008^{\mathrm{a}}$ \\
\hline NBV (L) & $1.44 \pm 0.06$ & $1.42 \pm 0.06$ & $.036^{\mathrm{a}}$ \\
\hline $\mathrm{T} 2$ lesion volume $(\mathrm{mL})^{\mathrm{b}}$ & $6.2(2.4-14.9)$ & $6.9(2.2-13.6)$ & .644 \\
\hline \multicolumn{4}{|l|}{ Patients on IFNb/GA $(n=17)$} \\
\hline FA severity (z score) & $-0.64 \pm 0.43$ & $-0.67 \pm 0.48$ & .94 \\
\hline MD severity ( $z$ score) & $0.74 \pm 0.58$ & $0.78 \pm 0.58$ & .64 \\
\hline AD severity (z score) & $0.26 \pm 0.35$ & $0.26 \pm 0.28$ & 1.0 \\
\hline RD severity (z score) & $0.82 \pm 0.59$ & $0.87 \pm 0.62$ & .43 \\
\hline NGMV (L) & $0.73 \pm 0.06$ & $0.74 \pm 0.05$ & 1.0 \\
\hline NWMV (L) & $0.69 \pm 0.04$ & $0.67 \pm 0.03$ & $.004^{\mathrm{a}}$ \\
\hline $\mathrm{NBV}(\mathrm{L})$ & $1.42 \pm 0.08$ & $1.41 \pm 0.07$ & $<.001^{\mathrm{a}}$ \\
\hline $\mathrm{T} 2$ lesion volume $(\mathrm{mL})^{\mathrm{b}}$ & $4.9(0.25-12.0)$ & $5.4(0.28-13.3)$ & $.012^{\mathrm{a}}$ \\
\hline
\end{tabular}

Note:-NGMV indicates normalized gray matter volume; NWMV, normalized white matter volume.

${ }^{a}$ Significant difference between the time points (Bonferroni-corrected).

${ }^{\mathrm{b}}$ Median and interquartile range.

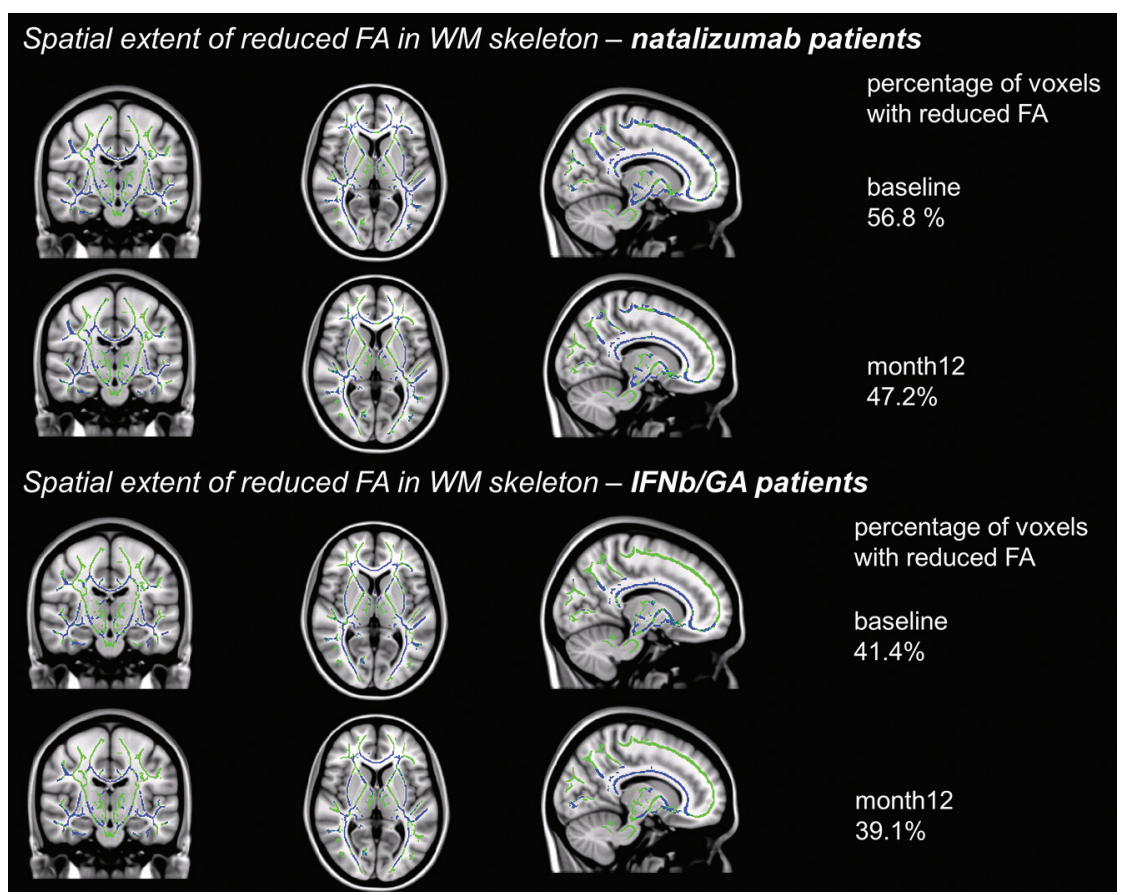

FIG 1. Spatial extent of lowered FA (in blue) of white matter voxels in the TBSS skeleton (green) ( $X=77, Y=109, Z=77$ ) of patients treated with natalizumab (upper 2 rows) and those treated with IFNb/GA (lower 2 rows). Patients starting natalizumab had reduced FA in $56.8 \%(P<.05)$ of the WM skeleton at baseline and improved to $47.2 \%$ at month 12 . Patients continuing IFNb/GA had reduced FA in $41.4 \%$ of the WM skeleton at baseline and $39.1 \%$ at month 12 .

Verbal Learning and Memory Task, in which only scores of patients receiving natalizumab declined with time $(P=.024)$, compared with a relatively stable score in patients receiving IFNb/GA.

In the total patient group (those receiving both natalizumab and IFNb/GA), a significant correlation was found between average cognition and the FA severity $z$ score $(r=0.525$, $P<.001$ at month 12; On-line Figure), indicating that patients with more severe WM damage have worse cognitive impairment.

\section{DISCUSSION}

In this longitudinal study, the clinical and radiologic evolution of patients with MS initiating natalizumab treatment was monitored for 12 months. Additionally, we also followed age-, sex-, and disabilitymatched patients with MS continuing IFNb/GA and healthy controls. In natalizumab-treated patients, the severity of WM damage and depressive symptoms improved during 12 months, while lesion volumes and disability levels remained constant. In patients treated with IFNb/ GA, lesion volumes and disability levels worsened, with no improvement in WM damage or depression. Both patient groups had reduced normalized WM volume and NBV at month 12 .

Previous in vivo studies have shown FA reductions in focal lesions in MS, as well as in the normal-appearing white matter, ${ }^{6,21}$ though increases with time have not previously been reported. In animal models, reduced FA was found to be the result of less axonal integrity (related to $\mathrm{AD}^{22,23}$ ) or demyelination (related to $\mathrm{RD}^{24,25}$ ). This finding was confirmed in a postmortem histopathologic DTI study of MS brain sections showing a strong correlation of FA with the level of myelination as well as the number of axons in both WM lesions and normal-appearing white matter. ${ }^{26}$ Because we have observed increases in FA with time, the strong antiinflammatory effect of natalizumab, ${ }^{27}$ in which leukocytes are prevented from penetrating the blood-brain barrier, may therefore have led to a more advantageous environment for axonal repair and remyelination in the normal-appearing white matter. This supposition was supported by a previous study on natalizumab, in which FA values within gadolinium-enhancing WM lesions were found to increase with time. Additionally, in this study, FA decreases were in normal-appearing brain tissue in this time period (pooled ROIs of normal-appearing white matter and GM). ${ }^{28}$ In the current study, however, we did not differentiate between lesional WM and normal-appearing white matter and we did not observe decreases in FA in the natalizumab group. Future work is required to specifically follow diffusion metrics in lesional WM under natalizumab treatment because the anti-inflammatory effect could particularly prevent damage or improve integrity in preactive or active lesions but could not be investigated in the current study because we did not have sufficient gadolinium-enhanced MR images available. 


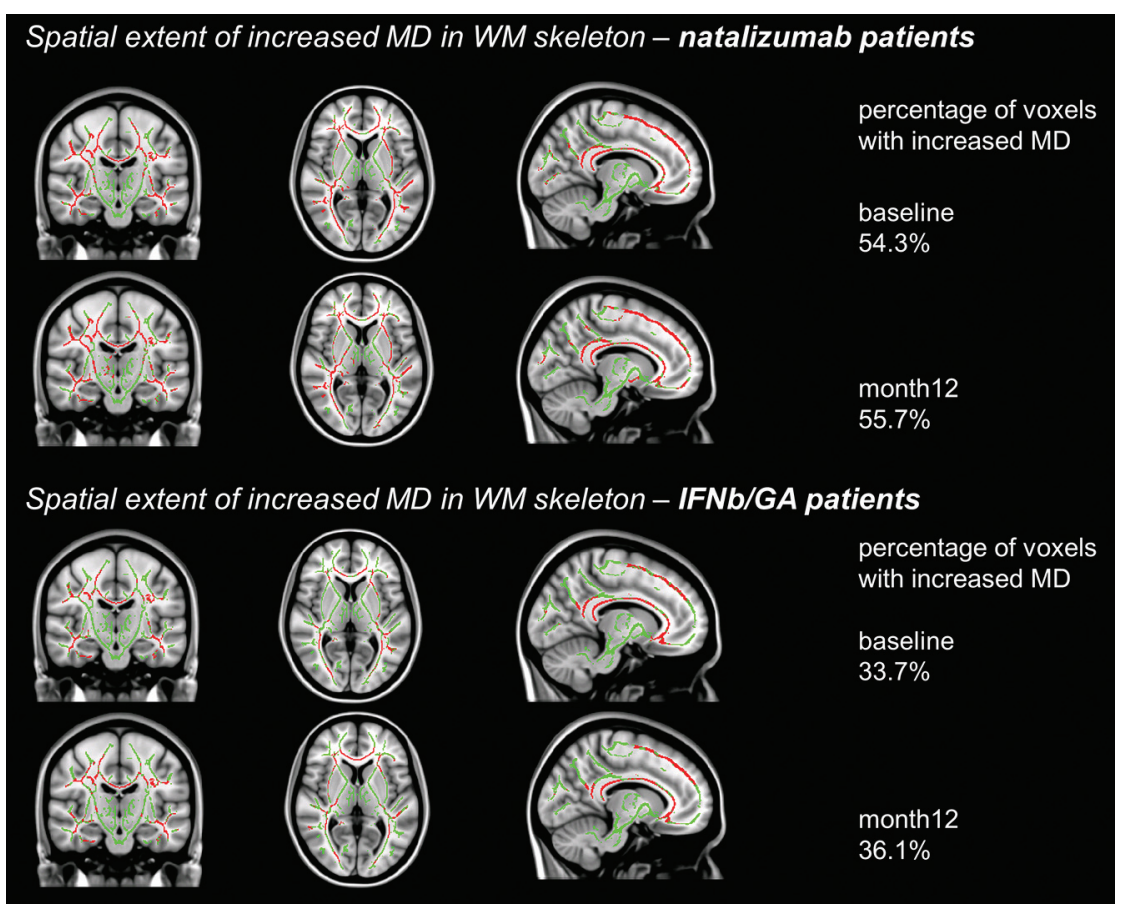

FIG 2. Spatial extent of increased MD (in red) in white matter voxels in the TBSS skeleton (green) $(X=101, Y=109, Z=77$ ) of patients treated with natalizumab (upper 2 rows) and those treated with IFNb/GA (lower 2 rows). Patients starting natalizumab had increased MD in 54.3\% $(P<.05)$ of the WM skeleton at baseline and $55.7 \%$ at month 12 . Patients continuing IFNb/GA had increased MD in $33.7 \%$ of the WM skeleton at baseline and $36.1 \%$ at month 12 .

Table 4: RCI (mean) of patients on natalizumab and IFNb/GA between baseline and month 12

\begin{tabular}{lccc}
\hline \multicolumn{1}{c}{ RCI Baseline-Month 12 } & Patients on Natalizumab & Patients on IFNb/GA & $\boldsymbol{P}$ Value \\
\hline Symbol Digit Modalities Test & $-0.02 \pm 0.68$ & $-0.04 \pm 0.77$ & .993 \\
SPART-total & $0.18 \pm 1.46$ & $-0.49 \pm 1.42$ & .432 \\
SPART-delayed & $0.54 \pm 1.69$ & $0.06 \pm 1.99$ & .629 \\
VLGT-immediate recall & $-0.67 \pm 0.88$ & $0.20 \pm 1.03$ & $.024^{\mathrm{a}}$ \\
VLGT-short-term free recall & $-0.15 \pm 1.01$ & $0.06 \pm 0.75$ & .575 \\
VLGT-long-term free recall & $-0.21 \pm 1.36$ & $0.47 \pm 0.84$ & .211 \\
WLG-Animals & $0.15 \pm 0.90$ & $-0.40 \pm 0.81$ & .185 \\
WLG-Professions & $-0.19 \pm 0.88$ & $0.04 \pm 1.17$ & .835 \\
WLG-4 letter "M" words & $-0.61 \pm 0.88$ & $-0.36 \pm 1.08$ & .129 \\
Digit Span Forward & $-0.01 \pm 0.87$ & $0.06 \pm 0.85$ & .842 \\
Digit Span Backward & $-0.31 \pm 0.89$ & $-0.34 \pm 1.42$ & .572 \\
TMT-Letter-Number Switching & $0.41 \pm 3.23$ & $0.59 \pm 2.91$ & .922 \\
Stroop-interference & $-1.00 \pm 2.14$ & $-0.78 \pm 1.63$ & .595 \\
\hline
\end{tabular}

Note:-SPART indicates Spatial Recall Task; VLGT, Verbal Memory and Learning Task; WLG, Word List Generation; TMT, Trail-Making Test.

${ }^{a}$ A significant difference between the patient groups.

Both patient groups had reduced normalized WM volume and NBV at the month 12. In the patients receiving natalizumab, this finding might be caused by the well-known pseudoatrophy effect, in which the anti-inflammatory effect of natalizumab reduces the edema during the first 12 months of treatment.9,29,30

Clinically, natalizumab appeared to stabilize EDSS scores and reduce symptoms of depression, as observed in our data. No effect on cognitive functioning was found in this study. Although the patients receiving natalizumab had a significantly lower RCI in only 1 subtest (short-term verbal memory) compared with patients receiving IFNb/GA, the score of patients receiving natalizumab, in an absolute sense, at month 12 was comparable with the baseline. This outcome is in contrast to previous studies showing improvement in cognition under natalizumab treatment with a short treatment window. ${ }^{31-37}$ In those studies, however, no controls were included and scores were not corrected for normal learning effects, such as by using the RCI. Here, both patient and control groups showed positive learning curves in most tests (see RCI scores in Table 4). This finding indicates normal improvement in raw cognitive scores with time, stressing the need for healthy control scores for future longitudinal studies looking at cognition in MS.

If the observed increases in FA persist for longer follow-up times, it is possible that natalizumab-induced improvement and/or stabilizations in brain tissue could affect cognitive function in these patients, given the strong correlation between the severity of FA abnormalities and overall cognition found in our data, as well as in other previous studies $^{5,7,38}$ and the previously shown slow rate of cognitive decline in MS. ${ }^{39}$ It is currently unclear, however, whether this could be in the form of actual increases in cognitive scores or merely the slowing down of cognitive decline. Therefore studies with longer follow-up times are needed. Future studies could also investigate regional WM FA changes and possibly GM FA changes (which we did not investigate in this study) and correlate these potential improvements to change in cognition.

The nonrandomized observational study design and a relatively small study population might be seen as limitations of the current study. Patients starting natalizumab might have a more severe disease (as natalizumab is a second-line therapy at our center), though in our study sample, the patient groups did not differ in physical disability, cognitive performance, disease duration, lesion load, or the severity of FA damage of the whole skeleton. Patients receiving natalizumab did show a higher extent of FA damage in WM compared with those receiving IFNb/GA (56.8\% versus $41.4 \%$ ) however. Therefore, we did not directly compare patient groups but merely added the interferon- $\beta$ and glatiramer acetate groups, in which clinical and MR imaging effects seem to be similar, ${ }^{40}$ to illustrate longitudinal changes in the MS brain that occur in patients with less aggressive disease. Besides the study design, the relatively short follow-up time indicates the need for future studies with longer treatment windows and larger sample sizes, per- 
haps by using a baseline measurement after several months of anti-inflammatory treatment, to reduce the effects of acute inflammation. This need is especially indicated for studies looking at cognitive decline in MS.

\section{CONCLUSIONS}

We found that after 12 months of natalizumab treatment, patients with MS showed a reduction in the severity of WM damage, combined with a stabilization of EDSS scores and lesion loads and improved depressive symptoms. Carefully matched patients receiving IFNb/GA did not have reduced WM damage, showing larger lesion volumes and worsened disability. Future studies with longer follow-up times are now required to investigate the longterm effects of these improvements on clinical measures like cognition in MS.

Disclosures: Menno Schoonheim—UNRELATED: Consultancy: Genzyme*; Grants/ Grants Pending: Dutch MS Research Foundation, ${ }^{*}$ Comments: The MS Center Amsterdam was supported by grants from the Dutch MS Research Foundation; Payment for Lectures (including service on Speakers Bureaus): Excellence in Medical Education, ${ }^{*}$ Comments: Our center has received financial compensation for lectures I have given for Excellence in Medical Education to Neurologists on several occasions. Hanneke Hulst-UNRELATED: Consultancy: Biogen Idec,* Teva Pharmaceutical Industries, Genzyme, ${ }^{*}$ Novartis, ${ }^{\star}$ Merck Serono. ${ }^{\star}$ Chris Polman—RELATED: Grant: Biogen Idec; UNRELATED: Board Membership: Receptos/PPD, MorphoSys; Consultancy: Actelion, Biogen Idec, GlaxoSmithKline, Merck Serono, Novartis, Teva Pharmaceutical Industries*; Grants/Grants Pending: Biogen Idec, ${ }^{*}$ Bayer Schering, ${ }^{*}$ Novartis, ${ }^{\star}$ Teva Pharmaceutical Industries. * Frederik Barkhof-UNRELATED: Board Membership: Radiology, Neurology, Brain; Consultancy: Roche, Novartis, Synthon, Teva Pharmaceutical Industries, ${ }^{*}$ Schering, Merck Serono, Biogen Idec, Comments: advice to pharmaceutical companies. Jeroen Geurts_UNRELATED: Board Membership: MSJ editorial work*; Consultancy: Hertie Foundation,* National MS Society, ${ }^{*}$ Biogen, ${ }^{*}$ Novartis, ${ }^{*}$ Teva Pharmaceutical Industries*; Grants/Grants Pending: Biogen, ${ }^{*}$ Novartis, ${ }^{*}$ Dutch Foundation MS Research, ${ }^{*}$ Canadian MS Society. * Money paid to the institution.

\section{REFERENCES}

1. Compston A, Coles A. Multiple sclerosis. Lancet 2008;372:1502-17 CrossRef Medline

2. Geurts JJ, Calabrese M, Fisher E, et al. Measurement and clinical effect of grey matter pathology in multiple sclerosis. Lancet Neurol 2012;11:1082-92 CrossRef Medline

3. Schulz D, Kopp B, Kunkel A, et al. Cognition in the early stage of multiple sclerosis. J Neurol 2006;253:1002-10 CrossRef Medline

4. Chiaravalloti ND, DeLuca J. Cognitive impairment in multiple sclerosis. Lancet Neurol 2008;7:1139-51 CrossRef Medline

5. Hulst HE, Steenwijk MD, Versteeg A, et al. Cognitive impairment in MS: impact of white matter integrity, gray matter volume, and lesions. Neurology 2013;80:1025-32 CrossRef Medline

6. Roosendaal SD, Geurts JJ, Vrenken H, et al. Regional DTI differences in multiple sclerosis patients. Neuroimage 2009;44:1397-403 CrossRef Medline

7. Schoonheim MM, Vigeveno RM, Rueda Lopes FC, et al. Sex-specific extent and severity of white matter damage in multiple sclerosis: implications for cognitive decline. Hum Brain Mapp 2014;35: 2348-58 CrossRef Medline

8. Dineen RA, Vilisaar J, Hlinka J, et al. Disconnection as a mechanism for cognitive dysfunction in multiple sclerosis. Brain 2009;132: 239-49 Medline

9. Miller DH, Soon D, Fernando KT, et al; RM Investigators. MRI outcomes in a placebo-controlled trial of natalizumab in relapsing MS. Neurology 2007;68:1390-401 CrossRef Medline

10. Polman $\mathrm{CH}, \mathrm{O}$ 'Connor PW, Havrdova E, et al; RM Investigators. A randomized, placebo-controlled trial of natalizumab for relapsing multiple sclerosis. NEngl J Med 2006;354:899-910 CrossRef Medline

11. Kurtzke JF. Rating neurologic impairment in multiple-sclerosis: an expanded disability status scale (EdSS). Neurology 1983;33:1444-52 CrossRef Medline

12. Polman CH, Reingold SC, Edan G, et al. Diagnostic criteria for multiple sclerosis: 2005 revisions to the "McDonald Criteria." Ann Neurol 2005;58:840-46 Medline

13. Steenwijk MD, Pouwels PJ, Daams M, et al. Accurate white matter lesion segmentation by $\mathrm{k}$ nearest neighbor classification with tissue type priors (kNN-TTPs). Neuroimage Clin 2013;3:462-69 CrossRef Medline

14. Smith SM, Zhang Y, Jenkinson M, et al. Accurate, robust, and automated longitudinal and cross-sectional brain change analysis. $\mathrm{Neu}$ roimage 2002;17:479-89 Medline

15. Chard DT, Jackson JS, Miller DH, et al. Reducing the impact of white matter lesions on automated measures of brain gray and white matter volumes. J Magn Reson Imaging 2010;32:223-28 CrossRef Medline

16. Smith SM, Jenkinson M, Johansen-Berg H, et al. Tract-based spatial statistics: voxelwise analysis of multi-subject diffusion data. Neuroimage 2006;31:1487-505 Medline

17. Rao SM, Leo GJ, Bernardin L, et al. Cognitive dysfunction in multiple-sclerosis, 1: frequency, patterns, and prediction. Neurology 1991;41:685-91 Medline

18. Walker LAS, Mendella PD, Stewart A, et al. Meaningful change in cognition in multiple sclerosis: method matters. Can J Neurol Sci 2011;38:282-88 Medline

19. Vercoulen JH, Swanink CM, Fennis JF, et al. Dimensional assessment of chronic fatigue syndrome. J Psychosom Res 1994;38:383-92 Medline

20. Zigmond AS, Snaith RP. The hospital anxiety and depression scale. Acta Psychiatr Scand 1983;67:361-70 Medline

21. Bammer R, Augustin M, Strasser-Fuchs S, et al. Magnetic resonance diffusion tensor imaging for characterizing diffuse and focal white matter abnormalities in multiple sclerosis. Magn Reson Med 2000; 44:583-91 Medline

22. Budde MD, Xie M, Cross $\mathrm{AH}$, et al. Axial diffusivity is the primary correlate of axonal injury in the experimental autoimmune encephalomyelitis spinal cord: a quantitative pixelwise analysis. J Neurosci 2009;29:2805-13 CrossRef Medline

23. Budde MD, Kim JH, Liang HF, et al. Toward accurate diagnosis of white matter pathology using diffusion tensor imaging. Magn Reson Med 2007;57:688-95 Medline

24. Song SK, Sun SW, Ramsbottom MJ, et al. Dysmyelination revealed through MRI as increased radial (but unchanged axial) diffusion of water. Neuroimage 2002;17:1429-36 Medline

25. Song SK, Yoshino J, Le TQ, et al. Demyelination increases radial diffusivity in corpus callosum of mouse brain. Neuroimage 2005;26: 132-40 Medline

26. Schmierer K, Wheeler-Kingshott CA, Boulby PA, et al. Diffusion tensor imaging of post mortem multiple sclerosis brain. Neuroimage 2007;35:467-77 Medline

27. Yednock TA, Cannon C, Fritz LC, et al. Prevention of experimental autoimmune encephalomyelitis by antibodies against alpha 4 beta 1 integrin. Nature 1992;356:63-66 Medline

28. Fox RJ, Cronin T, Lin J, et al. Measuring myelin repair and axonal loss with diffusion tensor imaging. AJNR Am J Neuroradiol 2011;32: 85-91 CrossRef Medline

29. Magraner M, Coret F, Casanova B. The relationship between inflammatory activity and brain atrophy in natalizumab treated patients. Eur J Radiol 2012;81:3485-90 CrossRef Medline

30. Sastre-Garriga J, Tur C, Pareto D, et al. Brain atrophy in natalizumab-treated patients: a 3-year follow-up. Mult Scler 2015;21: 749-56 CrossRef Medline

31. Iaffaldano P, Viterbo RG, Paolicelli D, et al. Impact of natalizumab on cognitive performances and fatigue in relapsing multiple sclerosis: a prospective, open-label, two years observational study. PLoS One 2012;7:e35843 CrossRef Medline

32. Lang C, Reiss C, Mäurer M. Natalizumab may improve cognition and mood in multiple sclerosis. Eur Neurol 2012;67:162-66 CrossRef Medline

33. Mattioli F, Stampatori C, Bellomi F, et al. Natalizumab efficacy on 
cognitive impairment in MS. Neurol Sci 2011;31(suppl 3):321-23 CrossRef Medline

34. Mattioli F, Stampatori C, Capra R. The effect of natalizumab on cognitive function in patients with relapsing-remitting multiple sclerosis: preliminary results of a 1-year follow-up study. Neurol Sci 2011;32:83-88 CrossRef Medline

35. Portaccio E, Stromillo ML, Goretti B, et al. Natalizumab may reduce cognitive changes and brain atrophy rate in relapsing-remitting multiple sclerosis: a prospective, non-randomized pilot study. Eur J Neurol 2013;20:986-90 CrossRef Medline

36. Stephenson JJ, Kern DM, Agarwal SS, et al. Impact of natalizumab on patient-reported outcomes in multiple sclerosis: a longitudinal study. Health Qual Life Outcomes 2012;10:155 CrossRef Medline
37. Svenningsson A, Falk E, Celius EG, et al; Tynergy Trial Investigators. Natalizumab treatment reduces fatigue in multiple sclerosis: results from the TYNERGY trial—a study in the real life setting. PLoS One 2013;8:e58643 CrossRef Medline

38. Yu HJ, Christodoulou C, Bhise V, et al. Multiple white matter tract abnormalities underlie cognitive impairment in RRMS. Neuroimage 2012;59:3713-22 CrossRef Medline

39. Weinstein A, Schwid SR, Schiffer RB, et al. Neuropsychologic status in multiple sclerosis after treatment with glatiramer. Arch Neurol 1999;56:319-24 Medline

40. La, ML, Di Pietrantonj C, Rovaris, M, et al. Interferons-beta versus glatiramer acetate for relapsing-remitting multiple sclerosis. Cochrane Database Syst Rev 2014;7:CD009333 CrossRef Medline 